\title{
Antioxidant and Anti-hyperlipidemic Effects of Bark Extract of Pinus eldarica in Dexamethasone-induced Dyslipidemic Rats
}

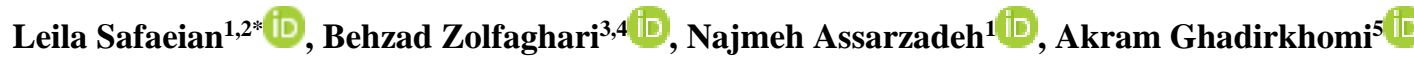

1. Depatment of Pharmacology and Toxicology, School of Pharmacy and Pharmaceutical Sciences, Isfahan University of Medical Sciences, Isfahan, Iran

2. Department of Research and Development, Vice Chancellery for Food and Drug, Isfahan University of Medical Sciences, Isfahan, Iran

3. Department of Pharmacognosy, School of Pharmacy and Pharmaceutical Sciences, Isfahan University of Medical Sciences, Isfahan, Iran

4. Isfahan Pharmaceutical Sciences Research Center, Isfahan University of Medical Sciences, Isfahan, Iran

5. Office for Supervision on Food, Cosmetics and Hygienic Products, Vice Chancellery for Food and Drugs, Isfahan University of Medical Sciences, Isfahan, Iran

\begin{tabular}{|c|}
\hline Article Info \\
\hline doi) 10.30699/jambs.27.125.49 \\
\hline $\begin{array}{c}\text { Received: 2019/11/20; } \\
\text { Accepted: 2019/11/27; } \\
\text { Published Online: } 30 \text { Nov 2019; }\end{array}$ \\
\hline $\begin{array}{l}\text { Use your device to scan and read the } \\
\text { article online }\end{array}$ \\
\hline
\end{tabular}

Corresponding Information: Leila Safaeian, Department of Pharmacology and Toxicology, School of Pharmacy and Pharmaceutical Sciences, Isfahan University of Medical Sciences, Isfahan, Iran

E-Mail: leila_safaeian@pharm.mui.ac.ir

\begin{abstract}
Background \& Objective: Although Pinus eldarica is considered as a pine with many valuable phytochemical constituents, little is known about the pharmacological effects of its bark extract. Therefore, the present study aimed to evaluate in vivo antioxidant activity and also the possible beneficial effects of the bark extract of $P$. eldarica on dexamethasone-induced dyslipidemia in rats.
\end{abstract}

Materials \& Methods: Total phenolic content was determined using Folin-Ciocalteu method. The in vivo antioxidant assays included the measurement of hydroperoxides level and ferric reducing antioxidant power (FRAP) value in plasma samples of rats receiving intraperitoneal injections (IP) injections of plant extract (100, 200 and 400 $\mathrm{mg} / \mathrm{kg})$ for 28 days. For induction of dyslipidemia, dexamethasone $(10 \mathrm{mg} / \mathrm{kg})$ was subcutaneously administered during 8 days. Different doses of extract were given orally plus dexamethasone in three groups of animals. Serum lipids, blood glucose and malondialdehyde (MDA) levels and liver histopathology were assessed.

Results: High total phenolic content was determined as $375 \pm 1.2 \mathrm{mg}$ gallic acid equivalent/ $\mathrm{g}$ of dried bark extract. The extract significantly decreased plasma hydroperoxides level at all doses and increased FRAP value at the dose of $400 \mathrm{mg} / \mathrm{kg}$ during in vivo antioxidant analysis. $P$. eldarica led to a significant reduction in serum levels of blood glucose, total cholesterol, triglyceride and MDA and improved liver histopathological changes at the doses of 200 and $400 \mathrm{mg} / \mathrm{kg}$ in dyslipidemic rats.

Conclusion: These findings suggest the potential antioxidant, antihyperlipidemic and antihyperglycemic activities for the bark extract of $P$. eldarica which may be due to the high amounts of phenolic compounds.

Keywords: Antioxidants, Dexamethasone, Hyperlipidemias, Lipid Peroxidation, Pinus eldarica

\section{Introduction}

Hyperlipidemia is considered as a risk factor in developing cardiovascular diseases (CVDs) such as atherosclerosis (1). Atherosclerosis or hardening of the arteries plays a prominent role in several deadly cardiovascular or cerebrovascular disorders (2).

Oxidative stress as a result of the overproduction of free radicals and low power of antioxidant defense system is also involved in the pathogenesis of CVD (3). In vasculature, reactive oxygen species (ROS) lead to nitric oxide (NO) inactivation, low-density lipoprotein (LDL) oxidation, and consequently endothelial dysfunction or apoptosis (4,5). Recent investigations have focused on herbal medicines and natural products for developing novel cholesterol lowering agents with antioxidant activities due to their desirable efficacy and relatively fewer complications (6).

Pine family (Pinaceae) includes a large number of widespread conifers with almost 250 species in 11 genera. Pinus as the most important genus in the Pinaceae family has about $115-120$ species of coniferous trees and grows widely in different countries including Iran (7). 
Pinus eldarica Medw. or Iranian pine is a popular tree with evergreen foliage leaves and thick, gray and reddish-brown bark, which belongs to Pinaceae and is broadly planted in Iran (8). In folk medicine, different parts of this tree are used for treating asthma and skin illnesses $(9,10)$. The nut extract of $P$. eldarica has some pharmacological properties including anti-hyperglycemic, anti-hyperlipidemic, anti-atherosclerotic and anti-urolithiatic (11-13). We previously reported the in vitro antioxidant and cytoprotective effects for the bark extract of $P$. eldarica (14). Phytochemical studies indicated the high presence of polyphenolic compounds such as catechin, taxifolin, ferulic acid and caffeic acid in P. eldarica bark (15). However, little is known about the pharmacological effects of the bark extract of $P$. eldarica. Considering the great biological activities of polyphenolic compounds, the present study aimed to investigate the in vivo antioxidant activity and also the possible beneficial effects of the bark extract of $P$. eldarica on serum lipid profile, glucose level, and oxidative status in dexamethasone (Dex)-induced dyslipidemia in rats.

\section{Materials and Methods}

\section{Plant Material and Preparation of Extract}

The barks of $P$. eldarica were obtained from pine trees in Isfahan (Isfahan Province of Iran) on July 2018. The specimen voucher (No. 3318) was authenticated by a botanist and located at the Herbarium of our School.

The hydroalcoholic extract was prepared by maceration method using ethanol $(70 \%)$ at room temperature for $72 \mathrm{hr}$ in three times. After filtration and removing the solvent with a vacuum rotary evaporator, the yield extract was freeze-dried and the extract powder was kept at $-20^{\circ} \mathrm{C}$.

\section{Determination of Total Phenolic Content}

Folin-Ciocalteu colorimetric assay was used for the measurement of total phenolic content in the bark extract of $P$. eldarica using a mixture solution of phosphomolybdate and phosphotungstate. In brief, 20 $\mu \mathrm{L}$ of the extract $(2.5 \mathrm{mg} / \mathrm{mL})$ was diluted with distilled water to $1.58 \mathrm{~mL}$ and mixed with Folin-Ciocalteu reagent $(100 \mu \mathrm{L})$ and sodium carbonate $(300 \mu \mathrm{L}, 20 \%)$. After $2 \mathrm{hr}$ incubation, the absorbance was determined using spectrophotometer at $765 \mathrm{~nm}$. The results were calculated using a calibration curve of gallic acid and stated as milligram of gallic acid equivalent (GAE) per gram of the extract (16).

\section{Animals}

Male Wistar albino rats weighing $250 \pm 20$ gr were maintained under the standard environmental conditions including room temperature range of 20$25^{\circ} \mathrm{C}$ and regular light/dark cycle of $12 \mathrm{hr} / 12 \mathrm{hr}$. They were allowed for free access to water and feed. The rats were acclimatized with the experimental environment for 1 week before the test. The experimental protocol was approved by the Biomedical Researches Ethics Committee of Isfahan University of Medical Sciences (ethical approval ID: IR.MUI.REC.1396.2.091).

\section{In vivo Antioxidant Assay}

For evaluation of the antioxidant effect of $P$. eldarica bark extract in rats, doses of 100, 200 and $400 \mathrm{mg} / \mathrm{kg}$ of the extract were administered daily intraperitoneally (i.p.) for 28 days (11). The control rats received i.p. injection of the vehicle daily. Each group consisted of 6 rats. At the end of the experiment, the blood was taken from orbital sinus plexus under anesthesia and the plasma was isolated for further testing.

\section{Measurement of Hydroperoxides Concentration}

The effect of $P$. eldarica bark extract on the plasma hydroperoxides of rats as the indicator for reactive molecules was measured using xylenol orange reagent1 (FOX-1) method. In brief, the FOX1 reagent containing ammonium ferrous sulfate and xylenol orange in aqueous medium with sorbitol was added to $10 \mu \mathrm{L}$ of the plasma samples. After incubation of mixture for $30 \mathrm{~min}$ at $37^{\circ} \mathrm{C}$, the absorbance of solution was determined at 540-560 nm. The level of hydroperoxides in plasma samples was calculated in term of $\mu$ mole/ $\mathrm{L}$ of hydrogen peroxide $\left(\mathrm{H}_{2} \mathrm{O}_{2}\right)$ equivalents using a standard curve of $\mathrm{H}_{2} \mathrm{O}_{2}(17)$.

\section{Ferric Reducing Antioxidant Power Assay}

Ferric reducing antioxidant power (FRAP) assay was used for evaluation of the total antioxidant capacity in rats' plasma samples after treatment with different doses of $P$. eldarica bark extract. This colorimetric assay evaluates the reduction of ferric-tripyridyl triazine (TPTZ) complex in FRAP reagent to ferrous form. Briefly, plasma samples $(10 \mu \mathrm{L})$ were mixed with FRAP reagent and incubated for $40 \mathrm{~min}$ at $37^{\circ} \mathrm{C}$. Then, the absorbance was measured at $570 \mathrm{~nm}$. The FRAP value in plasma samples was calculated in term of $\mathrm{mmol} / \mathrm{L}$ of ferrous sulphate equivalents using a standard curve of $\mathrm{FeSO}_{4}$ (18).

\section{Evaluation of Antidyslipidemic Effects}

Dexamethasone-induced dyslipidemia was used for evaluation of the possible antidyslipidemic effects of $P$. eldarica bark extract. Dexamethason $(10 \mathrm{mg} / \mathrm{kg})$ was injected subcutaneously (s.c.) for 7 days in dyslipidemic control rats (19). Different doses of the extract $(100,200$ and $400 \mathrm{mg} / \mathrm{kg}$ ) were given orally plus dexamethasone in the treatment groups. Control group received s.c. injection of normal saline and orally administration of the vehicle extract. The reference group received dexamethasone and standard treatment of atorvastatin $(40 \mathrm{mg} / \mathrm{kg}$, orally) for 7 days. At the end of the experimental period, the blood samples of overnight fasted rats were taken and the serum was isolated for biochemical analysis. Then, animals were sacrificed and the livers were separated and kept immersed in $10 \%$ formalin and processed for histopathological examinations. 


\section{Biochemical Analysis for Dyslipidemia}

Serum lipid profile including triglycerides (TG), total cholesterol (TC) and high-density lipoprotein (HDL) was enzymatically estimated using particular biochemical kits (Pars Azmoon Co., Iran). The following formula was used to calculate LDL: LDL = Cholesterol - (Triglyceride/5) - HDL. The blood glucose level was measured using glucose oxidase method.

\section{Lipid Peroxidation Assay}

The serum lipid peroxidation was assessed through measuring malondialdehyde (MDA) concentration. First, the serum samples were mixed with trichloroacetic acid (20\%). Then, $\mathrm{H}_{2} \mathrm{SO}_{4}$ was added for the dispersion of precipitate. After adding a solution of thiobarbituric acid $(0.67 \%)$ in $\mathrm{Na}_{2} \mathrm{SO}_{4}$ to the samples and heating the solution in a boiling water bath for 1 $\mathrm{hr}$, the mixture was rapidly cooled and mixed with $\mathrm{n}$ butanol. The absorbance of the colored solution was detected at $532 \mathrm{~nm}$ using a spectrophotometer. Finally, the results were estimated in term of $\mathrm{nmol} / \mathrm{mL}$ of MDA equivalents using a calibration curve of MDA tetrabutyl ammonium (20).

\section{Histopathological Analysis}

The formalin fixed liver samples were dehydrated and cleared in xylene. Then paraffin blocks were prepared and cut at $5 \mu \mathrm{m}$ thickness, stained with hematoxylin \& eosin and evaluated microscopically for histopathological changes.

\section{Statistical Analysis}

The results were stated as the mean \pm standard error of mean (SEM). The experimental groups were analyzed by one-way analysis of variance (ANOVA) followed by Tukey post-hoc test using the SPSS 18 (SPSS Inc., Chicago, IL., USA). The P-value $<0.05$ was considered as the level of significance.

\section{Results}

\section{Total Phenolic Content}

Total phenolic content of $P$. eldarica bark extract was determined as $375 \pm 1.2 \mathrm{mg} \mathrm{GAE} / \mathrm{gr}$ of the dried plant extract.

Effect of $P$. eldarica Bark Extract on Hydroperoxides Concentration in Normal Rats

FOX1 method was used for evaluation of the effect of hydroalcoholic extract of $P$. eldarica bark on plasma hydroperoxides level in rats. The administration of $P$. eldarica bark extract for 28 days reduced the plasma hydroperoxides levels significantly at all doses of 100 $(P<0.01), 200 \quad(P<0.01)$ and $400 \mathrm{mg} / \mathrm{kg} \quad(P<0.001)$ compared to the control group (Figure 1).

Effect of $P$. eldarica Bark Extract on FRAP Value in Normal Rats

The FRAP value was used for the expression of plasma total antioxidant capacity in rats. $P$. eldarica bark extract increased the FRAP value significantly at the dose of $400 \mathrm{mg} / \mathrm{kg}$ compared to the control group $(P<0.05)$ after 28 days treatment (Figure 2).

Effect of $P$. eldarica Bark Extract on Biochemical Parameters in Dyslipidemic Rats

Table 1 illustrates the effect of treatment with $P$. eldarica bark extract on biochemical factors during dyslipidemia induced by dexamethasone. Significant elevations were observed in serum blood glucose $(P<0.01)$, TG $(P<0.05)$, TC $(P<0.05)$, and LDL level $(P<0.05)$ along with a major decrease in HDL level $(P<0.05)$ after administration of dexamethasone. Atorvastatin as a reference antihyperlipidemic drug reduced all the serum parameters of dyslipidemia and also increased HDL level significantly. Treatment of animals with $P$. eldarica bark extract at the doses of 200 and $400 \mathrm{mg} / \mathrm{kg}$ significantly reduced serum blood glucose $(P<0.05)$, TG $(P<0.01)$ and TC $(P<0.001$ and $P<0.01$, with respect to the doses of extract). However, no significant changes were observed in LDL and HDL levels after the treatment with $P$. eldarica bark extract.

Effect of P. eldarica Bark Extract on MDA Level in Dyslipidemic Rats

As indicated in Figure 3, there is a significant elevation in the serum MDA level as an indicator of lipid peroxidation in dyslipidemic rats compared to that in normal animals $(P<0.05)$. Administration of atorvastatin and doses of 100 and $200 \mathrm{mg} / \mathrm{kg}$ from $P$. eldarica bark extract decreased the MDA level significantly $(P<0.01)$.

\section{Effect of $P$. eldarica Bark Extract on Liver Histopathology}

Morphological examination of liver sections after administration of high dose of dexamethasone revealed histological changes including cellular swelling, fatty degeneration and diffused steatosis (Figure 4B). Normal architecture was observed in the liver of the control animals (Figure 4A). Treatment with atorvastatin (Figure $4 \mathrm{~F}$ ) and $P$. eldarica bark extract at the dose of $100 \mathrm{mg} / \mathrm{kg}$ (Figure 4C), $200 \mathrm{mg} / \mathrm{kg}$ (Figure 4D) and $400 \mathrm{mg} / \mathrm{kg}$ (Figure 4E) showed partially reduction in the histopathological changes of liver induced by dexamethasone. 


\begin{tabular}{|c|c|c|c|c|c|}
\hline Groups & BG (mg/dL) & TG (mg/dL) & TC (mg/dL) & HDL-C (mg/dL) & LDL-C (mg/dL) \\
\hline Normal control & $153.6 \pm 5.1$ & $129.1 \pm 9.6$ & $104.8 \pm 5.5$ & $44.2 \pm 8.0$ & $38.9 \pm 2.2$ \\
\hline Dexamethasone dyslipidemic control & $184.3 \pm 8.2^{\# \#}$ & $155.2 \pm 13.4^{\#}$ & $139.3 \pm 10.1^{\#}$ & $30.3 \pm 4.9^{\#}$ & $59.3 \pm 8.2^{\# \#}$ \\
\hline $\begin{array}{l}\text { Dexamethasone }+ \text { atorvastatin } \\
(40 \mathrm{mg} / \mathrm{Kg})\end{array}$ & $170.5 \pm 5.1^{\#}$ & $115.2 \pm 14.5^{* *}$ & $100.8 \pm 10.5^{* *}$ & $47.9 \pm 12.6^{* *}$ & $42.4 \pm 5.3^{* *}$ \\
\hline $\begin{array}{l}\text { Dexamethasone }+ \text { P. eldarica } \\
(100 \mathrm{mg} / \mathrm{Kg})\end{array}$ & $180.1 \pm 10.5^{\#}$ & $145.4 \pm 19.1$ & $115.1 \pm 16.1$ & $30.1 \pm 4.5^{\#}$ & $56.1 \pm 3.1^{\# \#}$ \\
\hline $\begin{array}{l}\text { Dexamethasone }+ \text { P. eldarica } \\
(200 \mathrm{mg} / \mathrm{Kg})\end{array}$ & $158.3 \pm 13.3^{*}$ & $124.6 \pm 6.7^{* *}$ & $93.3 \pm 11.3^{* * *}$ & $31.7 \pm 9.3^{\#}$ & $53.7 \pm 3.2^{\# \#}$ \\
\hline $\begin{array}{l}\text { Dexamethasone }+P . \text { eldarica } \\
(400 \mathrm{mg} / \mathrm{Kg})\end{array}$ & $159.2 \pm 18.1^{*}$ & $126.3 \pm 3.2^{* *}$ & $100.2 \pm 18.7^{* *}$ & $40.1 \pm 5.4$ & $54.3 \pm 4.5^{\# \#}$ \\
\hline
\end{tabular}

Values are expressed as means $\pm \mathrm{SD}(\mathrm{n}=6)$. Tukey post hoc analysis, ${ }^{\#} P<0.05$ versus normal control, ${ }^{\# \#} P<0.01$, ${ }^{\# \# \#} P<0.001$ versus normal control; ${ }^{*} P<0.05$ and ${ }^{* *} P<0.01$ versus dexamethasone-induced dyslipidemic control. BG, blood glucose; TG, triglyceride; TC, total cholesterol; LDL-C, low-density lipoprotein cholesterol; HDL-C, high-density lipoprotein cholesterol.

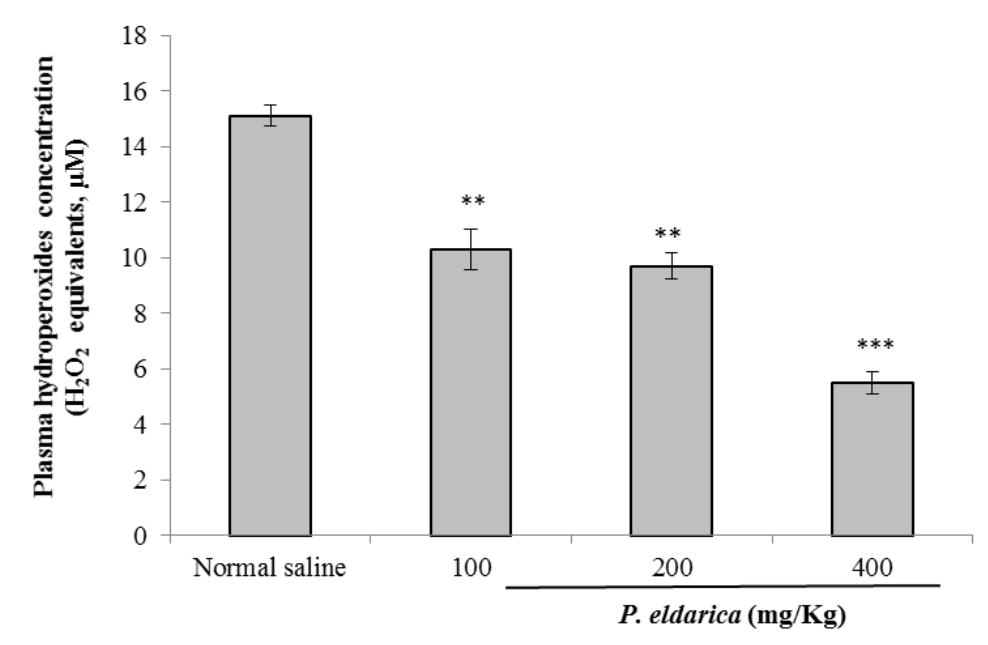

Figure 1. Plasma hydroperoxides concentrations (means \pm SEM, $\mathbf{N}=6$ ) after 28 days in rats treated with $P$. eldarica bark extract $(100-400 \mathrm{mg} / \mathrm{kg}) .{ }^{* * * *} P<0.001$ and ${ }^{* *} P<0.01$ versus control group treated with normal saline.

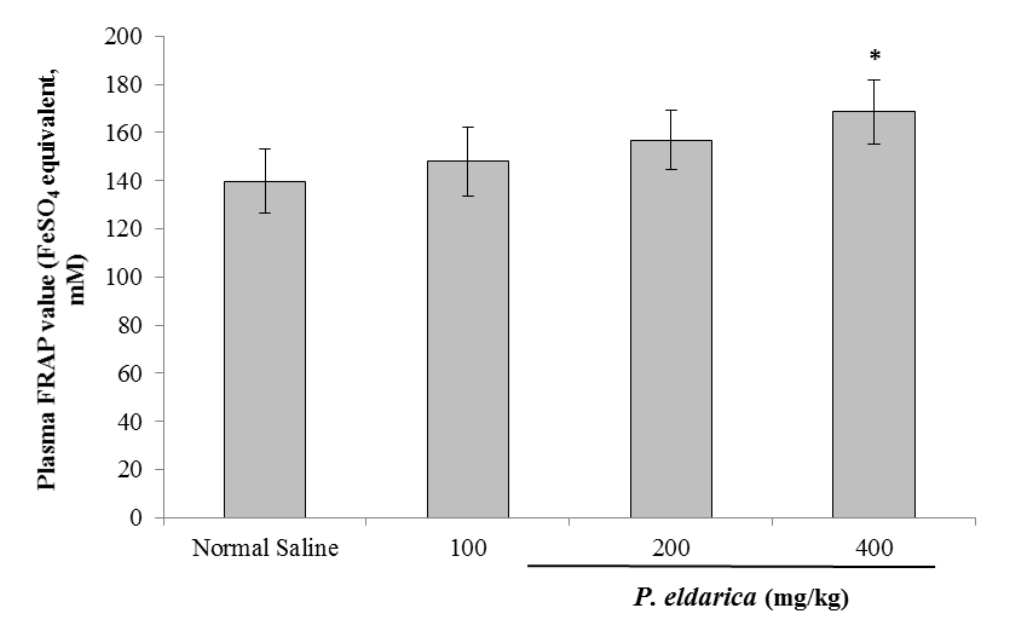

Figure 2. Plasma FRAP value (means $\pm \mathrm{SEM}, \mathrm{N}=6)$ after 28 days in rats treated with $P$. eldarica bark extract (100-400 $\mathrm{mg} / \mathrm{kg}) .{ }^{*} P<0.05$ versus control group treated with normal saline. 


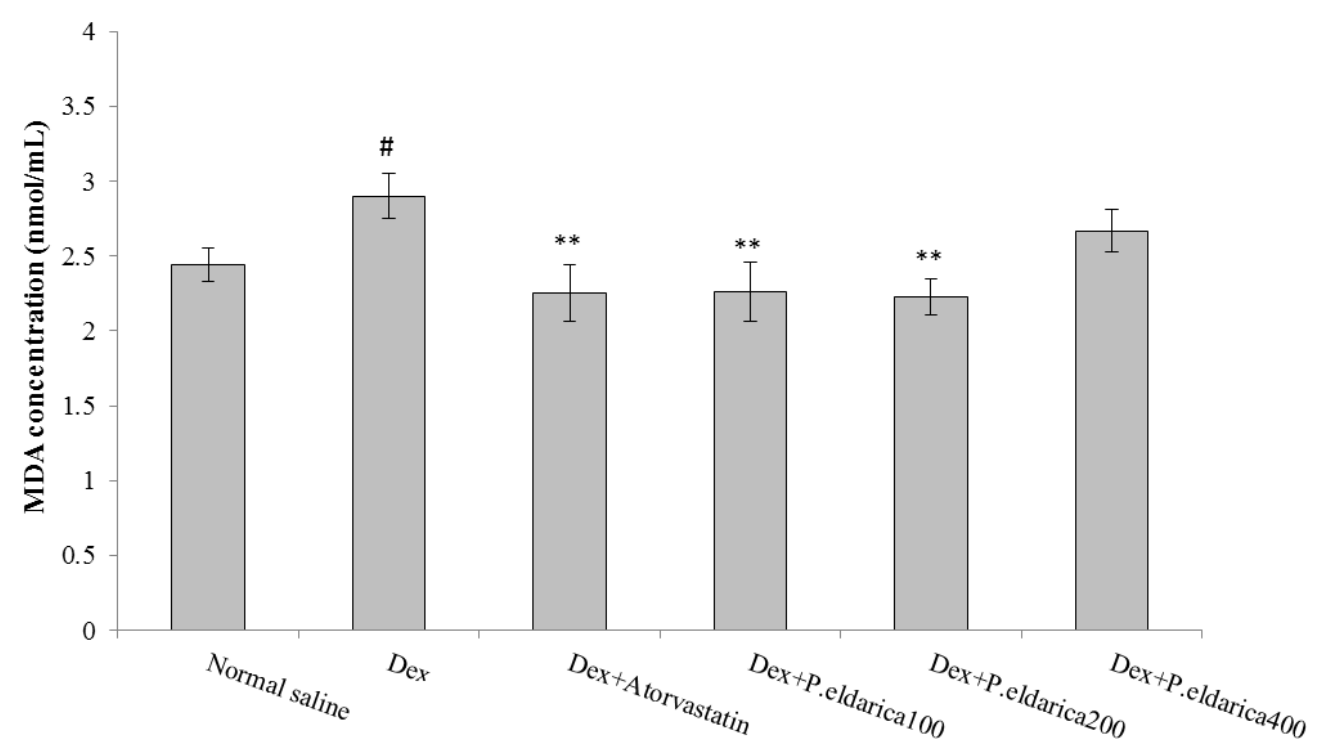

Figure 3. Effect of administration of $P$. eldarica bark extract $(100-400 \mathrm{mg} / \mathrm{kg})$ on serum MDA concentration (means \pm SEM, $N=6$ ) in dexamethasone-induced dyslipidemic rats. ${ }^{\#} P<0.05$ versus normal group, ${ }^{* *} P<0.01$ versus dexamethasoneinduced dyslipidemic group. MDA: Malondialdehyde.
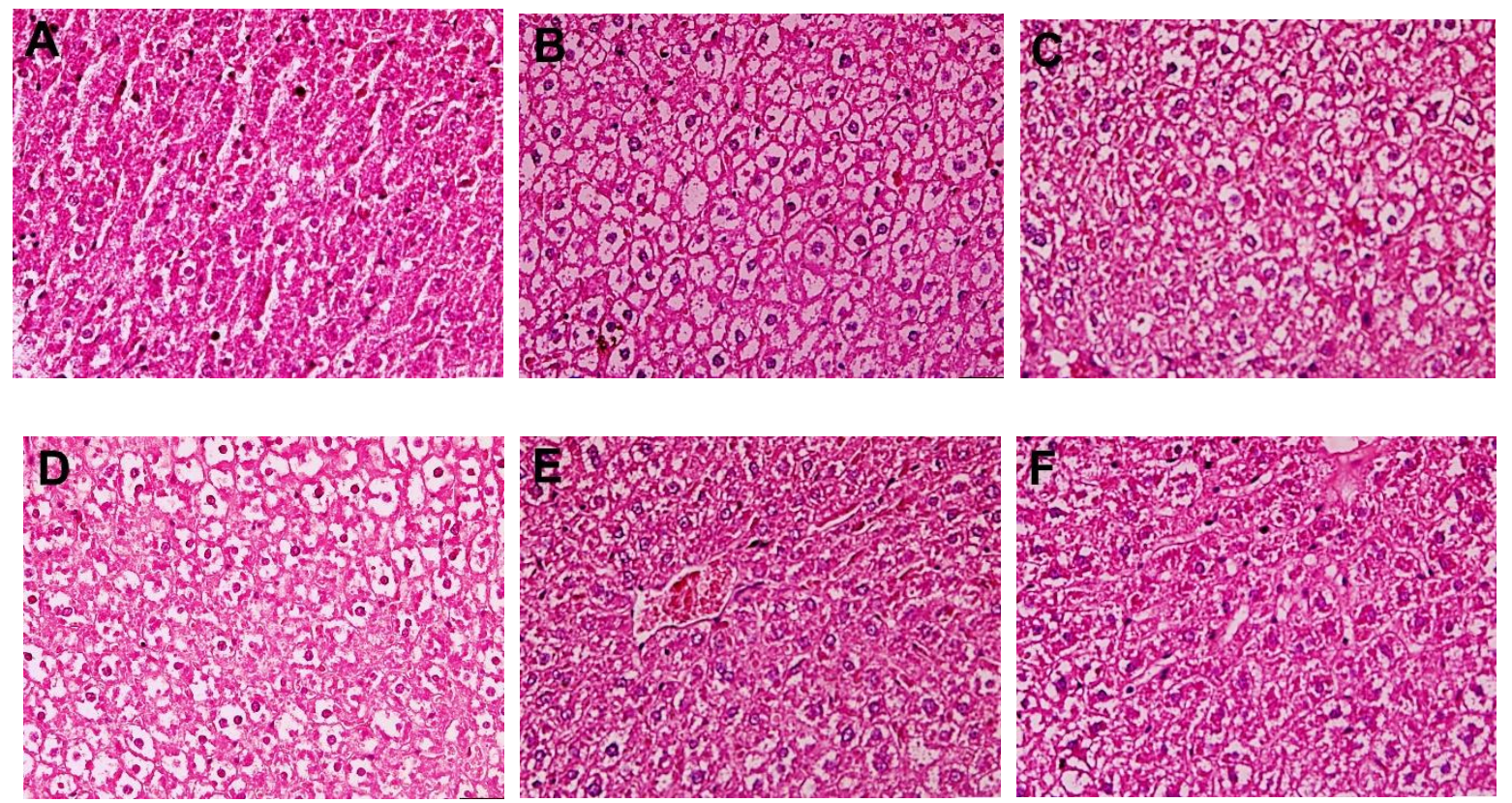

Figure 4. Representative photomicrograph of liver sections. Normal control group presenting normal histological structure (A), Dexamethasone-induced dyslipidemic group displaying diffused vesicular steatosis (B), $P$. eldarica bark extract treated groups with doses of $100 \mathrm{mg} / \mathrm{kg}$ (C) and $200 \mathrm{mg} / \mathrm{kg}$ (D) showing moderate vesicular steatosis and $400 \mathrm{mg} / \mathrm{kg} \mathrm{showing} \mathrm{mild}$ vesicular steatosis $(\mathrm{E})$, atorvastatin treated group showing low histopathological changes in hepatic architecture (F); H \& E, $\times 40$ magnification

\section{Discussion}

Findings of the present investigation demonstrated that the hydroalcoholic extract of $P$. eldarica bark has antioxidant, hypoglycemic and antihy-perlipidemic effects in dexamethasone-induced dyslipidemia. It is well known that oxidative stress, hyperglycemia, dyslipidemia and metabolic syndrome are considered as common problems during long-term treatment with high doses of glucocorticoids which are mainly due to

the high production of free radicals, insulin resistance and abnormalities in lipid metabolism $(21,22)$.

In this study, high amounts of phenolic compounds were detected in P. eldarica bark extract suggesting its potential therapeutic efficacy in various oxidativeinduced disorders especially cardiovascular diseases. Our results indicated in vivo antioxidant activities for $P$. eldarica bark extract through reducing the plasma 
hydroperoxides concentration and improving the total antioxidant capacity in normal rats and also declining the lipid peroxidation in dyslipidemic rats. Similarly, Bargi et al., discussed the protective effects of $P$. eldarica extract against the oxidative damage of hippocampal tissues in pentylenetetrazole-induced seizure model among rats (23).

These antioxidant properties may be related to the great quantities of phenolic compounds containing hydroxyl groups with high reactivity to metal ions and free radicals (15).

In the study of Sadeghi and co-workers which evaluated the bark, seed and needle of $P$. eldarica for the antioxidant components, the highest amount of total polyphenols was identified in the bark extract suggesting the valuable potential of this part of the plant for clinical use (24).

In the present study, the data related to assessing the antidyslipidemic effect revealed the ability of $P$. eldarica bark extract in decreasing serum TG, TC and blood glucose level and also improving the liver histopathological changes in dexamethasone-induced dyslipidemic rats.

Some investigations have described antidiabetic, anti-atherosclerotic and anti-hyperlipidemic activities for different parts of Pinus species including leaves, nuts, branches and barks. In this regard, antidiabetic effect has been reported for the essential oil of $P$. koraiensis leaves and the bark extract of $P$. pinaster and $P$. roxburghii (25-27). The branches extract of $P$. roxburghii has also shown the strong $\alpha$-glucosidase inhibitory activity in vitro (28).

The bark extract of $P$. pinaster has displayed antidislipidemic effect by reducing LDL and increasing HDL in animal and clinical studies $(29,30)$. Further, Kim et al, reported that the essential oil obtained from the extract of $P$. koraiensis leaves inhibits acylcoenzyme A: cholesterol acyltransferase and upregulates LDL receptor representing hypolipidemic activity (31).

Concerning P. eldarica, Fallahhuseini et al., have defined the antihyperglycemic effect for the nut extract of this plant in alloxan-induced diabetic rats without any effect on triglyceride and cholesterol levels (11). However, in their recent study, $P$. eldarica nut extract resulted in a significant decrease in blood cholesterol level in hypercholesterolemic rabbits (12).

The presence of bioactive constituents in the bark of $P$. eldarica including polyphenolics such as catechin, taxifolin, caffeic acid and ferulic acid and some monoterpenes and sesquiterpenes such as $\alpha$-pinene and $\beta$-caryophyllene may be responsible for the hypoglycemic and antihyperlipidemic activities of this plant (15). The beneficial effects on serum glucose and lipid profile have been recognized for catechins by controlling hemoglobin $\mathrm{A}(1 \mathrm{c})$ and lowering cholesterol and LDL levels (32). Taxifolin modulates the production and secretion of hepatic lipoproteins (33). Further, it protects diabetic animals by decreasing blood glucose and serum insulin level and improving the pathological alterations of kidneys via $\mathrm{NF}-\kappa \mathrm{B}$ pathway (34). Caffeic acid reduces the blood glucose level by elevating the glucose uptake and stimulating the insulin receptor signaling cascade, and inhibits hyperlipidemia by controlling the lipogenic enzymes in the liver $(35,36)$. Ferulic acid recovers glucose and lipid dysregulation through regulating the expression of lipogenic and gluconeogenic genes in the liver (37).

The major limitation of the present study was the lack of evaluating the mechanisms of antihyperglycemic and antihyperlipidemic effects of the $P$. eldarica bark extract because of financial budget restriction.

\section{Conclusion}

The present study indicated the in vivo antioxidant, hypoglycemic and hypolipidemic properties of hydroalcoholic extract of $P$. eldarica bark in dexamethasone-induced dyslipidemia. The observed effects are probably due to bioactive constituents especially the high amounts of phenolic compounds in the bark extract of this plant.

\section{Acknowledgments}

The authors are thankful to the Isfahan University of Medical Sciences for all supports. The project was supported by a grant No. 296091 from ViceChancellery for Research and Technology (Isfahan University of Medical Sciences).

\section{Conflict of Interest}

Authors declared no conflict of interest.

\section{References}

1. Shattat GF. A review article on hyperlipidemia: types, treatments and new drug targets. Biomed Pharmacol J. 2015;7:399-409. [DOI:10.13005/bpj/504]

2. Howard Alpe G, Sear J, Foex P. Methods of detecting atherosclerosis in non-cardiac surgical patients; the role of biochemical markers. $\mathrm{Br} \mathrm{J}$ Anaesth. 2006; 97: 758-69. [DOI:10.1093/bja/ael303] [PMID]

3. Navab M, Ananthramaiah G, Reddy ST, et al. Thematic review series: the pathogenesis of atherosclerosis the oxidation hypothesis of atherogenesis: the role of oxidized phospholipids and HDL. J Lipid Res. 2004; 45: 993-1007. [DOI:10.1194/jlr.R400001-JLR200] [PMID]

4. Schulz E, Anter E, Keaney J, John F. Oxidative stress, antioxidants, and endothelial function. Curr 
Med Chem. 2004; 11: 1093-104. [DOI:10.2174/0929867043365369] [PMID]

5. Peluso I, Morabito G, Urban L, Ioannone F, Serafi M. Oxidative stress in atherosclerosis development: the central role of LDL and oxidative burst. Endocr Metab Immune Disord Drug Targets. 2012; 12: 351-60. [DOI:10.2174/187153012803832602] [PMID]

6. Dhaliya S, Surya A, Dawn V, Betty C, Arun K, Sunil C. A review of hyperlipidemia and medicinal plants. Int JA PS BMS. 2013; 2: 219-37.

7. Gernandt DS, López GG, García SO, Liston A. Phylogeny and classification of Pinus. Taxon. 2005; 54: 29-42. [DOI:10.2307/25065300]

8. Zargary A. Medicinal plants )5th ed(. Tehran: Tehran University Press; 1996: 9-12.

9. Mamedov N, Gardner Z, Craker LE. Medicinal plants used in Russia and Central Asia for the treatment of selected skin conditions. J Herbs Spices Med Plants. 2005; 11: 191-222. [DOI:10.1300/J044v11n01_07]

10. Mamedov N, Craker LE. Medicinal plants used for the treatment of bronchial asthma in Russia and Central Asia. J Herbs Spices Med Plants. 2001; 8: 91-117. [DOI:10.1300/J044v08n02 03]

11. Mehrzadi S, Ghaznavi H, Tajallizadehkhoob Y, Fakhrzadeh H. Effects of Pinus eldarica Medw. nut extract on blood glucose and cholesterol levels in hypercholesterolemic alloxan-induced diabetic rats. J Med Plants. 2013; 1: 68-74.

12. Huseini HF, Anvari MS, Khoob YT, et al. Antihyperlipidemic and anti-atherosclerotic effects of Pinus eldarica Medw. nut in hypercholesterolemic rabbits. Daru. 2015; 23:32. [DOI:10.1186/s40199015-0114-9] [PMID] [PMCID]

13. Hosseinzadeh H, Khooei AR, Khashayarmanesh Z, Motamed-Shariaty V. Antiurolithiatic activity of Pinus eldarica medw: fruits aqueous extract in rats. Urol J. 2010; 7: 232-7.

14. Babaee F, Safaeian L, Zolfaghari B, Haghjoo Javanmard S. Cytoprotective effect of hydroalcoholic extract of Pinus eldarica bark against $\mathrm{H} 2 \mathrm{O} 2$-induced oxidative stress in human endothelial cells. Iran Biomed J. 2016; 20: 161-7. [DOI:10.4103/1735-5362.192488] [PMID] [PMCID]

15. Iravani S, Zolfaghari B. Phytochemical analysis of Pinus eldarica bark. Res Pharm Sci. 2014; 9: 243 50.

16. Yegdaneh A, Ghannadi A, Dayani L. Chemical constituents and biological activities of two Iranian Cystoseira species. Res Pharm Sci. 2016; 11: 311-7. [DOI:10.4103/1735-5362.189307] [PMID] [PMCID]
17. Wolff SP. Ferrous ion oxidation in presence of ferric ion indicator xylenol orange for measurement of hydroperoxides. Methods Enzymol. 1994; 233: 182-9. [DOI:10.1016/S00766879(94)33021-2]

18. Benzie IF, Strain JJ. The ferric reducing ability of plasma (FRAP) as a measure of "antioxidant power": the FRAP assay. Anal Biochem. 1996; 239: 70-6. [DOI:10.1006/abio.1996.0292] [PMID]

19. Kumar VR, Inamdar MN, Nayeemunnisa, Viswanatha GL. Protective effect of lemongrass oil against dexamethasone induced hyperlipidemia in rats: possible role of decreased lecithin cholesterol acetyl transferase activity. Asian Pac J Trop Med. 2011; 4: 658-60. [DOI:10.1016/S19957645(11)60167-3]

20. Mesripour A, Iyer A, Brown L. Mineralocorticoid receptors mediate cardiac remodelling in morphine-dependent rats. Basic Clin Pharmacol Toxicol. 2012; 111: 75-80. [DOI:10.1111/j.17427843.2012.00860.x] [PMID]

21. Bera S, Greiner S, Choudhury A, et al. Dexamethasone-induced oxidative stress enhances myeloma cell radiosensitization while sparing normal bone marrow hematopoiesis. Neoplasia. $\quad 2010 ; \quad$ 12: 980-92. [DOI:10.1593/neo.101146] [PMID] [PMCID]

22. Pragda SS, Kuppast I, Mankani K, Ramesh L. Evaluation of antihyperlipidemic activity of leaves of Portulaca oleracea Linn against dexamethasone induced hyperlipidemia in rats. Int J Pharm Pharm Sci. 2012; 4: 279-83.

23. Bargi R, Asgharzadehyazdi F, BeheshtI F, et al. The effects of hydroalcoholic extract of Pinus eldarica on hippocampal tissue oxidative damage in pentylenetetrazole-induced seizures in rat. Curr Nutr Food Sci. 2017; 13: 50-6. [DOI:10.2174/1573401312666161017142930]

24. Sadeghi Afjeh M, Fallah Huseini $H$, Tajalizadekhoob Y, Mirarefin M, Taheri E, Saeednia S. Determination of phenolic compounds in Pinus eldarica by HPLC. J Med Plants. 2014; 13: 22-33. [DOI:10.1055/s-0033-1352259]

25. Joo HE, Lee HJ, Sohn EJ, et al. Anti-diabetic potential of the essential oil of Pinus koraiensis leaves toward streptozotocin-treated mice and HIT-T15 pancreatic beta cells. Biosci Biotechnol Biochem. 2013; 77: 1997-2001. [DOI:10.1271/bbb.130254] [PMID]

26. Liu X, Wei J, Tan F, Zhou S, Wurthwein G, Rohdewald P. Antidiabetic effect of pycnogenol French maritime pine bark extract in patients with diabetes type II. Life Sci. 2004; 75: 2505-13. [DOI:10.1016/j.lfs.2003.10.043] [PMID] 
27. Kaushik P, Khokra S, Kaushik D. Evaluation of antidiabetic potential of Pinus roxburghii bark extract in alloxan induced diabetic rats. J Pharmacogn Nat Prod. 2015;1: 2-5. [DOI:10.4172/2472-0992.1000105]

28. El-Manawaty M, Gohar L. In vitro alphaglucosidase inhibitory activity of Egyptian plant extracts as an indication for their antidiabetic activity. In Vitro. 2018; 11: 360-7. [DOI:10.22159/ajpcr.2018.v11i7.25856]

29. Devaraj S, Vega-Lopez S, Kaul N, Schonlau F, Rohdewald P, Jialal I. Supplementation with a pine bark extract rich in polyphenols increases plasma antioxidant capacity and alters the plasma lipoprotein profile. Lipids. 2002; 37: 931-4. [DOI:10.1007/s11745-006-0982-3] [PMID]

30. Durackova Z, Trebaticky B, Novotny V, Zitnanova I, Breza J. Lipid metabolism and erectile function improvement by pycnogenol $\AA$, extract from the bark of pinus pinaster in patients suffering from erectile dysfunction-a pilot study. Nutr Res. 2003; 23: 1189-98. [DOI:10.1016/S0271-5317(03)00126-X]

31. Kim JH, Lee HJ, Jeong SJ, Lee MH, Kim SH. Essential oil of Pinus koraiensis leaves exerts antihyperlipidemic effects via up-regulation of low-density lipoprotein receptor and inhibition of acyl-coenzyme A: cholesterol acyltransferase. Phytother Res. 2012; 26: 1314-19. [DOI:10.1002/ptr.3734] [PMID]

32. Samavat H, Newman AR, Wang R, Yuan JM, Wu AH, Kurzer MS. Effects of green tea catechin extract on serum lipids in postmenopausal women: a randomized, placebo-controlled clinical trial.
Am J Clin Nutr. 2016; 104: 1671-82. [DOI:10.3945/ajen.116.137075] [PMID] [PMCID]

33. Kim A, Nam YJ, Lee CS. Taxifolin reduces the cholesterol oxidation product-induced neuronal apoptosis by suppressing the Akt and NF-kappaB activation-mediated cell death. Brain Res Bull. 2017; 134: 63-71.

[DOI:10.1016/i.brainresbull.2017.07.008] [PMID]

34. Theriault A, Wang Q, Van Iderstine SC, Chen B, Franke AA, Adeli K. Modulation of hepatic lipoprotein synthesis and secretion by taxifolin, a plant flavonoid. J Lipid Res. 2000; 41: 1969-79.

35. Huang DW, Shen SC, Wu JS. Effects of caffeic acid and cinnamic acid on glucose uptake in insulin-resistant mouse hepatocytes. J Agric Food Chem. 2009; 57: 7687-92. [DOI:10.1021/jf901376x] [PMID]

36. Liao CC, Ou TT, Wu CH, Wang CJ. Prevention of diet-induced hyperlipidemia and obesity by caffeic acid in C57BL/6 mice through regulation of hepatic lipogenesis gene expression. J Agric Food Chem. 2013; 61: 11082-8. [DOI:10.1021/if4026647] [PMID]

37. Naowaboot J, Piyabhan P, Munkong N, Parklak W, Pannangpetch P. Ferulic acid improves lipid and glucose homeostasis in high-fat diet-induced obese mice. Clin Exp Pharmacol Physiol. 2016; 43: 242-50. [DOI:10.1111/1440-1681.12514] [PMID]

\section{How to Cite This Article:}

Safaeian L, Zolfaghari B, Assarzadeh N, Ghadirkhomi A. Antioxidant and Anti-hyperlipidemic Effects of Bark Extract of Pinus Eldarica in Dexamethasone-induced Dyslipidemic Rats. J Adv Med Biomed Res. $2019 ; 27$ (125) :49-56

\section{Download citation:}

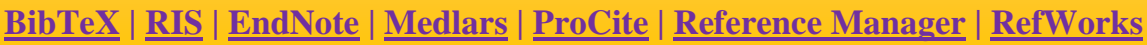

\section{Send citation to:}

Mendeley $2 \underline{\text { Zotero }}$ RefWorks $\underline{\text { RefWorks }}$ 